Volume 08, Nomor 03: $203-208$

Desember 2019

\title{
Penerapan Artificial Neural Network Terhadap Identifikasi Wajah Menggunakan Metode Backpropagation
}

\section{(Application of Artificial Neural Network on Face Identification using the Backpropagation Method)}

\author{
Mimin Hendriani ${ }^{*}$, Rais $^{1}$ dan Lilies Handayani ${ }^{1}$ \\ ${ }^{1}$ Program Studi Statistika, Jurusan Matematika, Fakultas MIPA, Universitas Tadulako, JI. Soekarno Hatta Km 9 Tondo \\ Palu Sulawesi Tengah 94118.
}

Keywords: Artificial Neural

Network, Backpropagation, Face Identification.

Keywords: Artificial Neural Network, Backpropagation, Identifikasi Wajah

${ }^{*}$ Coresponding Author : miminhendriani.ani@gmail.com

\begin{abstract}
Backpropagation is one of the supervised training methods that causes an error in the output produced. Backpropagation neural networks will be carried out in 3 stages, namely feedforward from input training patterns, backpropagation from errors related to adjustment of weights. Updating the weight is done when the training results obtained have not been converged. The value of the goal error (MSE) is 0.0070579 which is achieved at epochs to 99994 from the provisions of 100000 iterations. Based on the plot regression, the training data resulted in a correlation coefficient value of up to 0.55321 . The correlation coefficient value is concluded that the greater the $\mathrm{R}$ value produced, the better the level of accuracy in face identification carried out in this study.
\end{abstract}

\begin{abstract}
Abstrak
Backpropagation merupakan salah satu metode pelatihan terawasi yang menimbulkan error pada output yang dihasilkan. Jaringan syaraf tiruan backpropagation akan dilakukan dengan 3 tahapan yaitu feedforward dari pola pelatihan input, backpropagation dari kesalahan terkait penyesuaian dari bobot. Updating bobot dilakukan ketika hasil pelatihan yang diperoleh belum konvergen. Nilai error goal (MSE) sebesar 0.0070579 yang tercapai pada epochs ke 99994 dari ketetapan 100000 iterasi. Berdasarkan plot regression, pada training data yang dilakukan menghasilkan nilai koefisien korelasi hingga mencapai 0.55321 . Nilai koefisien korelasi tersebut disimpulkan bahwa semakin besar nilai $\mathrm{R}$ yang dihasilkan maka tingkat keakuratan pada identifikasi wajah yang dilakukan pada penelitian ini akan semakin baik.
\end{abstract}

\section{Latar Belakang}

Penelitian yang dilakukan berdasarkan penerapan jaringan syaraf tiruan dengan menggunakan metode backpropagation. Backpropagation memiliki beberapa unit yang ada dalam satu atau lebih layer tersembunyi, arsitekturnya terdiri atas input layer, hidden layer dan output layer. Seperti halnya model jaringan syaraf tiruan lain, backpropagation melatih jaringan untuk mendapatkan keseimbangan antara kemampuan jaringan untuk mengenali pola yang digunakan selama pelatihan serta kemampuan jaringan untuk memberikan respon yang benar terhadap pola masukan yang serupa dengan pola yang dipakai selama pelatihan (Siang, 2005).

Menurut Pamungkas, (2009), identifikasi wajah yang diteliti memiliki tujuannya sendiri termasuk demi keamanan terhadap oknum lain. Metode backpropagation sangat baik dalam menangani masalah pengenalan pola-pola secara kompleks. Selain itu metode ini juga termasuk dalam metode 
jaringan syaraf tiruan yang popular. identifikasi wajah dapat dilakukan dengan beberapa pola yaitu pola geometri, pola bentuk, pola warna dan pola tekstur.

Beberapa penelitian mengenai Artificial neural network dengan metode backpropagation telah dilakukan oleh Sofian (2017) dengan menerapkan jaringan syaraf tiruan menggunakan algoritma backpropagation, yang menghasilkan nilai koefisien korelasi (R) sebesar 0,99276 dengan nilai Mean Square Error (MSE) 0,00086145 dan epochs 99. Nilai koefisien korelasi nilai MSE yang dihasilkan pada proses pengujian menunjukkan bahwa jaringan syaraf tiruan backpropagation cukup baik. Selanjutnya, Abidin (2012) dengan merancang bangun sistem pengenalan ekspresi wajah menggunakan fisherface dan jaringan syaraf tiruan backpropagation yang menghasilkan keluaran yang nantinya dapat digunaka untuk menentukan jenis kelas ekspresi. Keluaran dari simulasi jaringan syaraf tiruan feedforward ini adalah vector kolom berukuran $7 \times 1$. Nilai $\geq 0.6$ akan dikonversi ke-1, sedangkan nilai $>0.6$ akan dikonversi ke 0 .

Jaringan syaraf tiruan dibentuk sebagai generalisasi model matamatika dari jaringan syaraf biologi, dengan asumsi bahwa pemrosesan informasi terjadi pada banyak elemen sederhana (neuron). Sinyal dikirimkan diantara neuron-neuron melalui penghubungpenghubung. Penghubung antara neuron memiliki bobot yang akan memperkuat atau memperlemah sinyal. Menentukan output, setiap neuron menggunakan fungsi aktivasi (biasanya bukan fungsi linear) yang dikenakan pada jumlahan input yang diterima. Besarnya output ini selanjutnya dibandingkan dengan suatu batas ambang (Ihwan,2013).

Jaringan syaraf tiruan menggunakan metode backpropagation juga dapat diterapkan dalam pengidentifikasian wajah. Sehingga, akan dilakukan penelitian tersebut. Dimana dalam penelitian ini, identifikasi wajah akan dilakukan dengan menggunakan citra.

\section{Bahan dan Metode}

Data yang digunakan dalam penelitian ini adalah data primer yang berasal hasil pengolahan aplikasi Matlab R2016a. Data diperoleh dengan cara mengambil beberapa citra dari beberapa objek yang akan digunakan. Objek yang digunakan pada penelitian berasal dari mahasiswa Fakultas matematika dan IImu Pengetahuan Alam Universitas Tadulako Program Studi Statistika. Data yang akan dihasilkan berbentuk pengelompokkan berdasarkan nilai $\mathrm{R}, \mathrm{G}, \mathrm{B}$ dari masing-masing citra penginputan pada aplikasi Matlab R2016a.

Tahapan penelitian yang akan digunakan pada penelitian ini akan dijelaskan sebagai berikut.

1. Membagi data menjadi dua bagian yaitu data training dan data testing.

- Data training digunakan untuk membentuk sebuah model classifier.

- Data testing digunakan untuk mengukur sejauh mana classifier berhasil melakukan klasifikasi dengan benar.

Selanjutnya data yang akan dianalisis adalah data training.

2. Normalisasi data, yaitu dengan meminimalkan data agar dapat bekerja dengan optimal.

3. Membangun jaringan, untuk membangun jaringan feedforward dengan banyak lapisan diperlukan algoritma backpropagation.

4. Penentuan nilai untuk mempengaruhi proses training

5. Proses training, yang dilakukan melibatkan objek jaringan, kumpulan data input dan data target sebagai input pelatihan dan akan menghasilkan objek jaringan terlatih, bobot-bobot akhir dan informasi selama pelatihan (epochs dan goal) sebagai output.

6. Hasil prediksi dilakukan dengan mensimulasi objek jaringan dan kumpulan data input.

7. Hasil performance prediksi, setelah mengetahui hasil prediksi selanjutnya akan ditampilkan output berupa grafis sehingga dapat terlihat lebih jelas.

8. Tingkat keakuratan hasil identifikasi wajah dengan pola RGB. Dilakukan klasifikasi dengan menggunakan data testing yang memiliki tingkat keakuratan tinggi sehingga dihasilkan angka keakuratan identifikasi.

\section{Hasil dan Pembahasan}

Hasil dan pembahasan pada bab ini akan dibahas mengenai citra yang dirubah menjadi numerik kemudian diolah sehingga mendapatkan hasil. Melakukan updating bobot pada Artificial Neural Network (ANN) dan mengetahui seberapa besar tingkat keakuratan untuk mengidentifikasi wajah dengan pola RGB (Red, Green, Blue) menggunakan metode backpropagation. Berikut merupakan hasil penelitian.

\section{Konversi Gambar}

Data yang digunakan diperoleh dari citra wajah pengurus HIMASTIKA (Himpunan Mahasiswa 
Statistika) periode ke tiga tahun 2018. Penelitian ini dilakukan dengan menggunakan bantuan software Matlab (R2016a), tujuannya yaitu untuk melihat seberapa besar tingkat keakuratan Artificial Neural Network (ANN) dalam mengidentifikasi wajah dengan pola RGB (Red, Green, Blue) menggunakan metode backpropagation.

Berdasarkan pada Gambar 1 pola RGB dari citra diperoleh kesimpulan bahwa masing-masing gambar memiliki ukuran berbeda yang dipengaruhi oleh warna. Semakin gelap warna pada citra maka objek pada citra akan semakin sulit terbaca sehingga ukuran background akan terlihat lebih luas. Berdasarkan Tabel 1 beberapa data hasil konversi gambar menjadi numerik.

Tabel 1 Data Konversi Citra ke Numerik

\begin{tabular}{|l|l|}
\hline$R$ & 187,637089 \\
\hline$G$ & 194,030449 \\
\hline$B$ & 199,9794531 \\
\hline
\end{tabular}

\section{Normalisi Data}

Normalisasi data dilakukan untuk memudahkan dalam mengolah guna melihat tingkat keakuratan. Normalisasi dapat dilakukan menggunakan rumus seperti pada persamaan berikut.

Dimana

$$
X^{\prime}=\frac{0.8(\mathrm{x}-\mathrm{a})}{\mathrm{b}-\mathrm{a}}+0.1
$$

$X^{\prime}=$ hasil normalisasi

$x=$ data awal

$a=$ nilai minimum awal

$b=$ nilai maximum awal

Hasil normalisasi dapat dilihat pada Tabel 2.

Tabel 2 Normalisasi Data Latih

\begin{tabular}{|l|l|r|}
\hline$R$ & 187,637089 & 0,635091 \\
\hline$G$ & 194,030449 & 0,667751 \\
\hline$B$ & 199,9794531 & 0,69814 \\
\hline
\end{tabular}

\section{Updating Bobot}

Updating bobot dilakukan ketika hasil pelatihan yang diperoleh belum konvergen. Tujuannya yaitu mencari titik konvergen pada penelitian tingkat keakuratan. Pengupdatean bobot dilakukan setelah melakukan pelatihan data terlebih dahulu. Berdasarkan Tabel 3.

\section{Tingat Keakuratan}

Metode backpropagation merupakan metode neural network dapat digunakan untuk pengidentifikasian data wajah. Pada penelitian ini ANN dengan metode backpropagation diterapkan untuk mengidentifikasi wajah guna melihat tingkat keakuratan berdasarkan pola RGB (Red, Green, Blue). Berdasarkan Gambar 2 Data ini diperoleh dari citra wajah yang kemudian diolah menggunakan Matlab sebanyak 258 data.

Tabel 3 Updating Bobot

\begin{tabular}{|l|}
\hline 0,618582545 \\
\hline 0,675660505 \\
\hline 0,673653572 \\
\hline 0,716926908 \\
\hline 0,672167031 \\
\hline
\end{tabular}

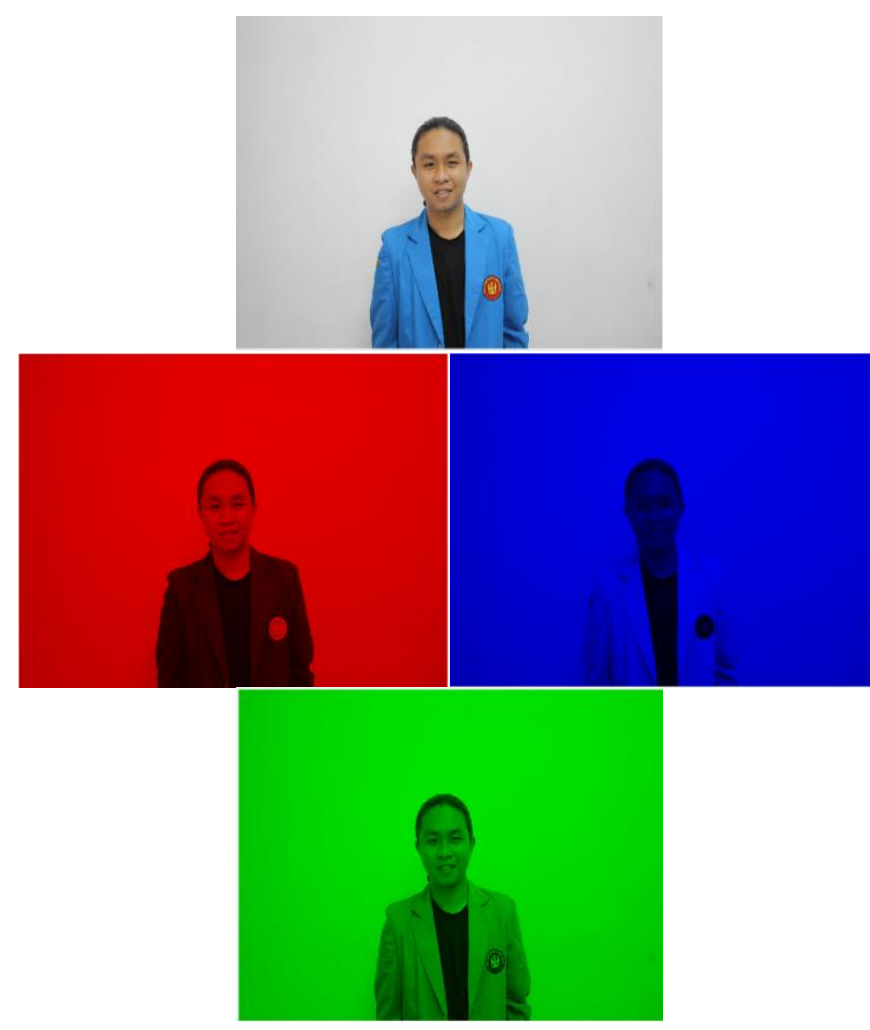

Gambar 1 Hasil Citra pola RGB

Berdasarkan grafik identifikasi wajah menunjukkan bahwa semakin banyaknya data, semakin banyak hidden layer dan semakin kecilnya angka goal akan memperlihatkan tingkat keakuratan yang semakin baik. Sebelum melihat hasil dari pengolahan dari penelitian ini. Beberapa kali telah dilakukan percobaan menggunakan jumlah data sama, jumlah hidden layer dan goal yang berbeda. Selanjutnya dilakukan sebanyak sebelas kali percobaan dengan jumlah goal sama yaitu sebesar 0.01 dan jumlah hidden layer berbeda mulai dari interval 5 hingga 55. Dalam percobaan tersebut ternyata menghasilkan nilai $R$ yang berbeda seperti pada Gambar 3. 


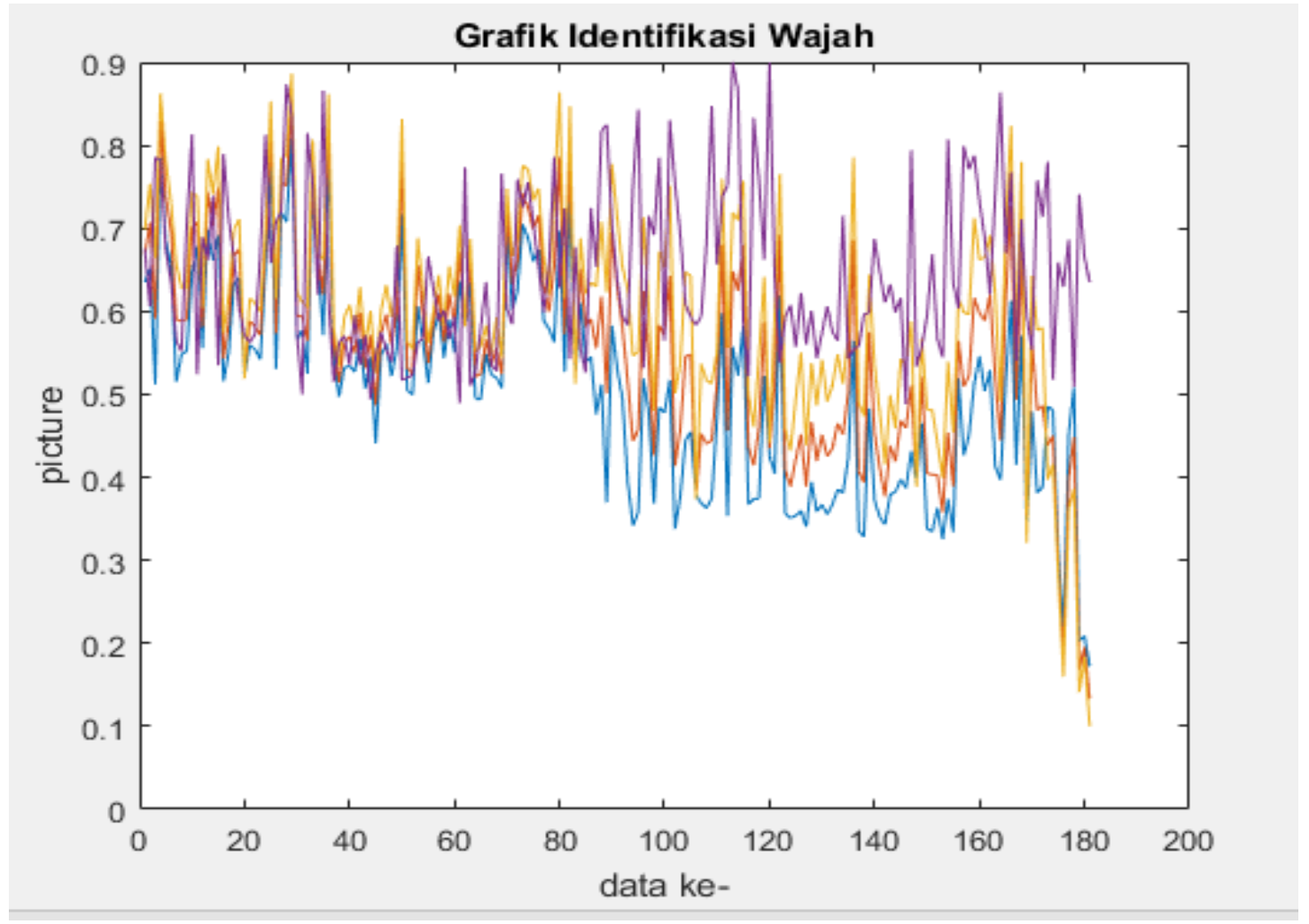

Gambar 2. Grafik Identifikasi Wajah

Berdasarkan grafik percobaan 1. menunjukkan bahwa semakin banyak hidden layer belum tentu akan semakin baik dalam mengidentifikasi. Pada grafik percobaan diatas terlihat dengan hidden layer sebanyak 15 menghasilkan nilai $R$ sebesar 0.27013 . Semakin tinggi nilai $\mathrm{R}$ maka akan semakin baik untuk digunakan. Percobaan ini akan teridentifikasi dengan baik apabila jumlah hidden layer sesuai dengan goal.

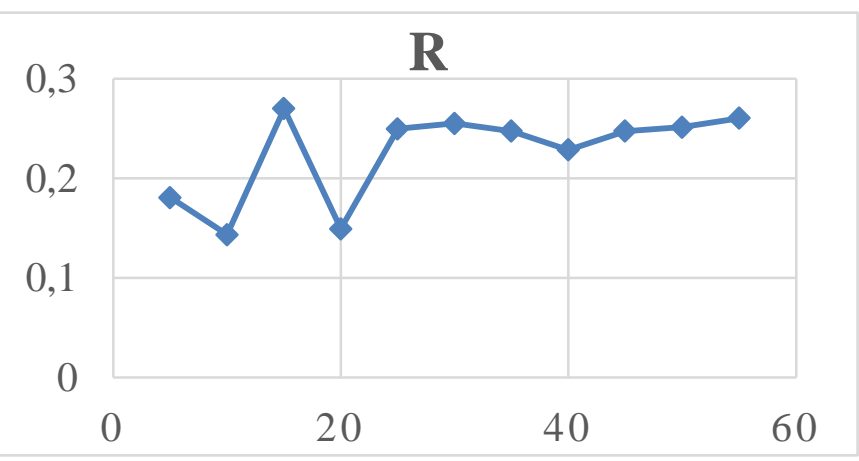

Gambar 3. Grafik Percobaan Penelitian 1

Setelah memperoleh hasil percobaan pertama, selanjutnya dilakukan percobaan dengan menggunakan nilai goal dan jumlah hidden layer yang berbeda. Berikut merupakan hasil percobaan yang dilakukan seperti pada grafik berikut.
Berdasarkan grafik percobaan 2 pada Gambar 4 dapat ditarik kesimpulan bahwa nilai $R$ tertinggi terdapat pada jumlah hidden layer 50, nilai goal sebesar 0.001 dan akan menghasilkan nilai $R$ sebesar 0.55321 .

Berdasarkan pada percobaan yang dilakukan menggunakan Matlab dari kedua percobaan dan telah ditampilkan dalam bentuk grafik dapat disimpulkan bahwa nilai $\mathrm{R}$ yang dapat digunakan terdapat pada percobaan kedua dengan jumlah hidden layer sebanyak 55 dan nilai goal 0.0001 menghasilkan nilai R sebesar 0.55321 .

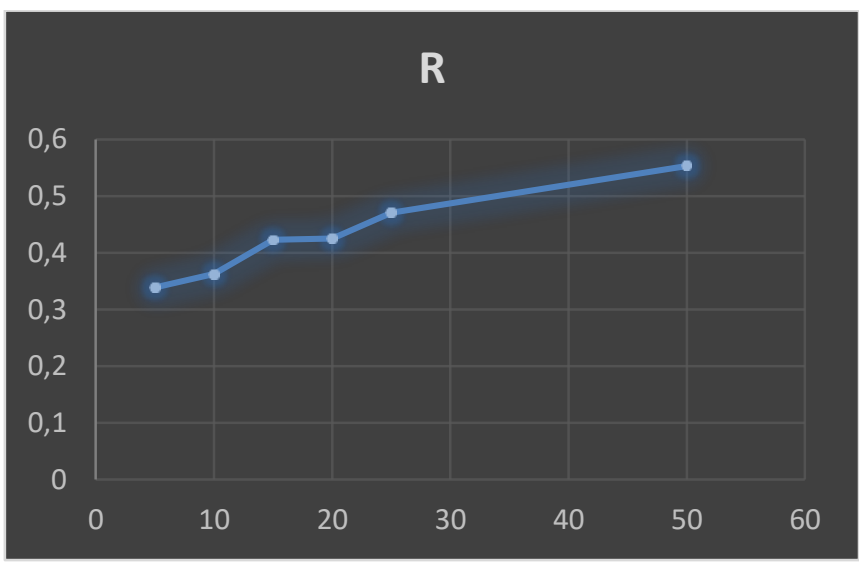

Gambar 4. Grafik Percobaan 2 


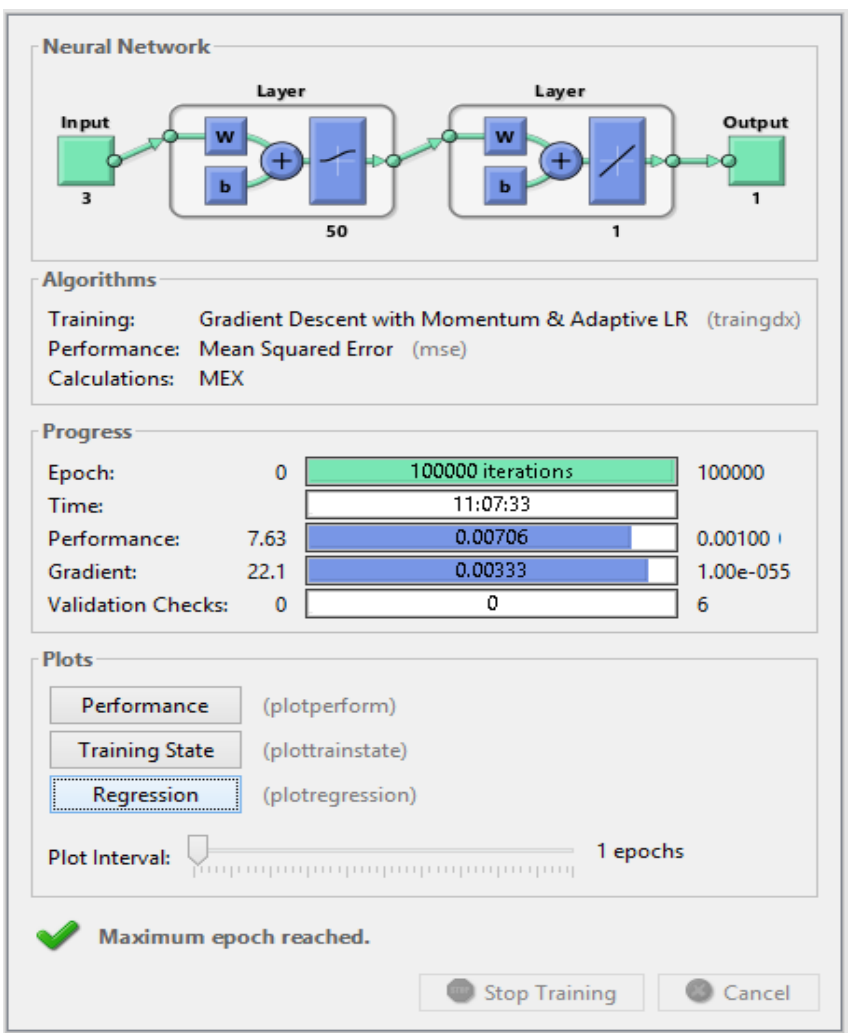

Gambar 5. Output training neural network

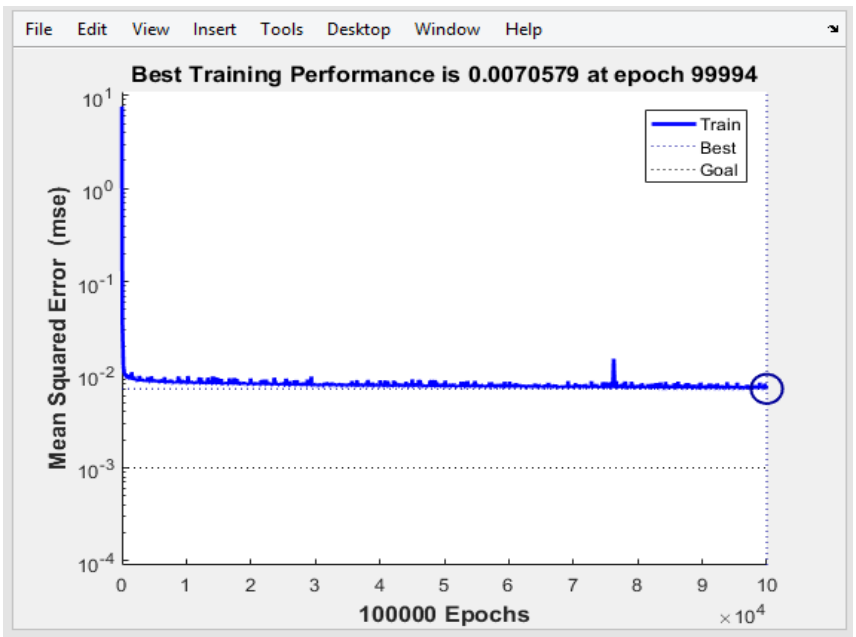

Gambar 6. Grafik Best Training Performance

Setelah melakukan percobaan menggunakan jumlah neuron yang berbeda maka ditetapkan jumlah neuron yang akan digunakan untuk melihat tingkat keakuratan dari citra wajah. Seperti pada gambar dibawah nilai epochs sebanyak 100000, goal ditentukan sebesar 0.001 untuk memperoleh hasil yang baik. Berdasarkan output training neural network pada Gambar 5 nilai untuk goal sebesar ditargetkan mencapai tingkat keakuratan hingga 0.001 , show 20 dan dalam jumlah iterasi sebanyak 100000 .

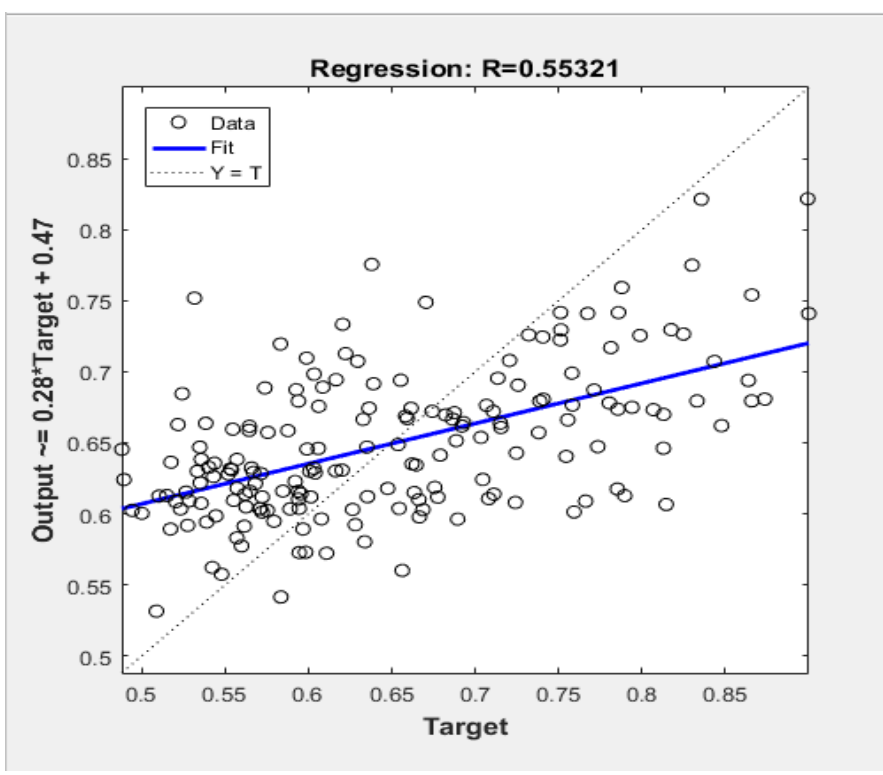

Gambar 7. Plot Regression
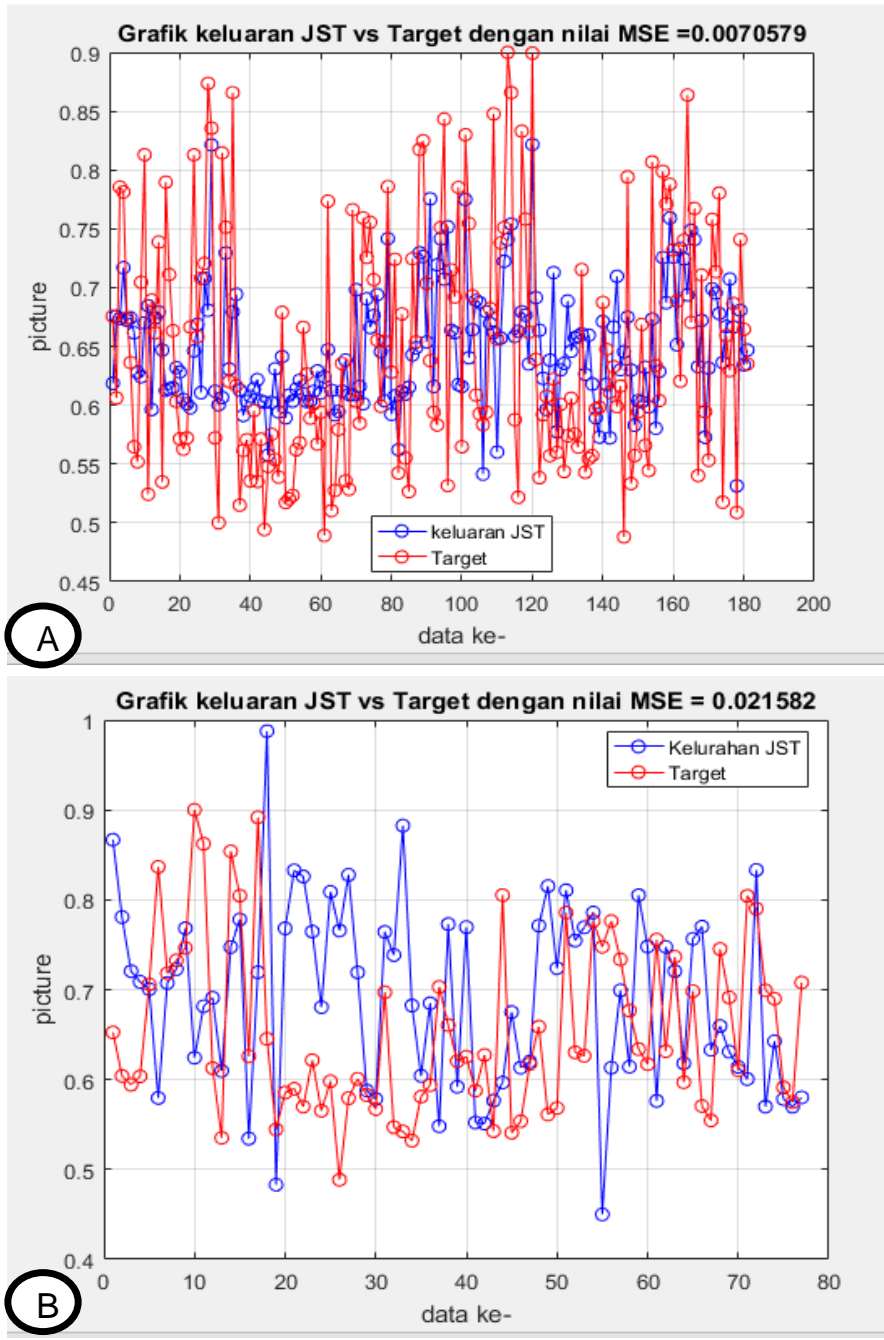

Gambar 8. Grafik perbandingan JST vs Target (A), Grafik Perbandingan Keluaran JST vs Target (B). 


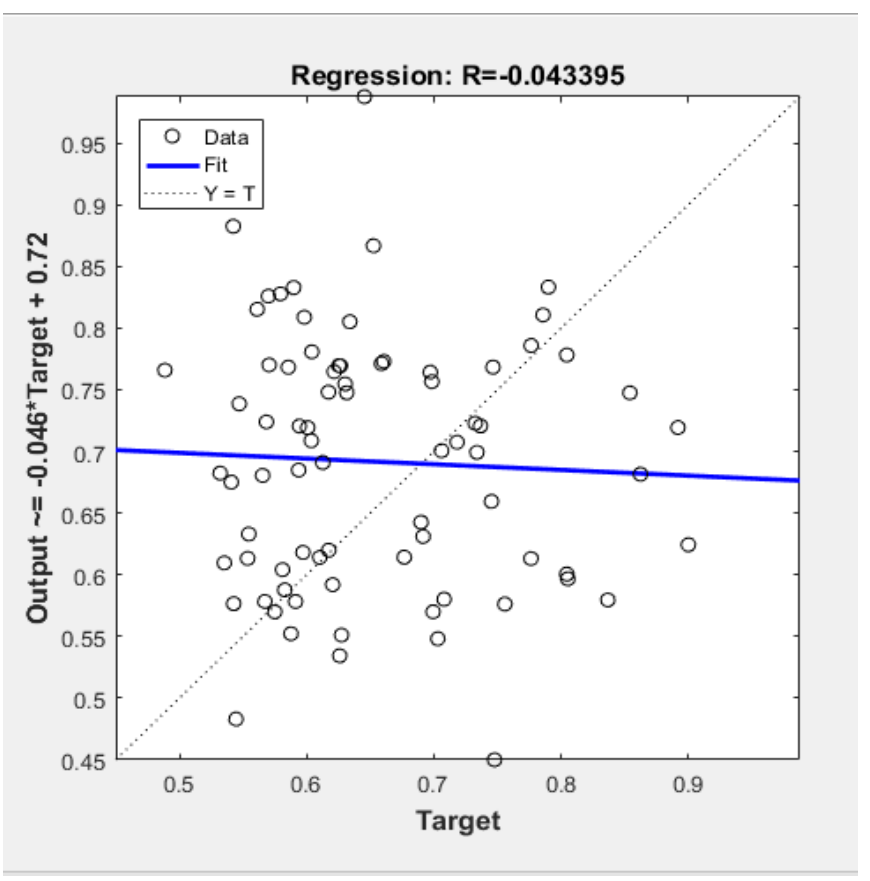

Gambar 9. Plot Regression Data Uji

Berdasarkan grafik training performance pada Gambar 6 memperlihatkan hasil pelatihan, nilai error goal (MSE) sebesar 0.0070579 yang tercapai pada epochs ke 99994 dari ketetapan 100000 iterasi. Berdasarkan plot regression, pada Gambar 7 training data yang dilakukan menghasilkan nilai koefisien korelasi hingga mencapai 0.55321 . Nilai koefisien korelasi tersebut disimpulkan bahwa semakin besar nilai $R$ yang dihasilkan maka tingkat keakuratan pada identifikasi wajah yang dilakukan pada penelitian ini akan semakin baik.

Berikut merupakan tampilan grafik keluaran jst dan target, nilai MSE yang tercapai sebesar 0.0070579 . Berdasarkan gambar 8A dapat disimpulakan bahwa nilai MSE sebesar 0.0070579 dapat dikatakan bahwa nilai koefisien korelasi dan nilai MSE yang diperoleh pada proses pelatihan tersebut dapat memperlihatkan tingkat keakutan wajah dengan pola RGB dengan baik. Cara yang digunakan hampir sama dengan cara untuk pelatihan data latih. Berikut merupakan output dari pelatihan menggunakan data uji. Berdasarkan hasil regresi pada Gambar 9 data uji menghasilkan nilai MSE yang hampir sama dengan plot regression data latih. Nilai MSE yang diperoleh yaitu sebesar (0.043395).

Berdasarkan grafik perbandingan keluaran jst dan target pada Gambar 8B diperoleh nilai MSE sebesar 0.021582 . Nilai koefisien korelasi dan nilai MSE yang dihasilkan menunjukkan bahwa jaringan syaraf tiruan backpropagation cukup baik untuk mengidentifikasi tingkat keakuratan wajah pola RGB.

\section{Ucapan Terimakasih}

Penulis mengucapkan terima kasih yang sebesarbesarnya kepada teman-teman yang telah mendukung selama penelitian.

\section{Daftar Pustaka}

Abidin. Z. (2012). Rancang Bangun Sistem Pengenalan Ekspresi Wajah Menghunakan Fishrerface dan Jaringan Syaraf Tiruan Backpropagation. (Jurnal MIPA), 35(Februari), 194-203.

Ihwan. A. (2013). Metode Jaringan Syaraf Tiruan Propagasi Balik Untuk Estimasi Curah Hujan Bulanan di Ketapang Kalimantan Barat. Prosiding Semirata FMIPA.

Siang. J.J (2005). Jaringan Syaraf Tiruan dan Pemrogramannya Menggunakan Matlab. Yogyakarta: Andi.

Pamungkas. A (2009). Pemrograman Matlab. Diperoleh dari website https://pemrogramanmatlab.com/pengolahancitra-digital/ekstraksi-ciri-citra-digital/ 